\title{
The Paradox of Public Service: Where Do We Draw the Line?
}

\section{Rebecca R. Martin}

Academic librarians today face a paradoxical dilemma: as the explosion of information continues and the tools available for accessing information increase in number and sophistication, we realize that we will be able to offer only a portion of such resources to our patrons. Given the growing importance of information in our society, the demands upon us can only increase. This paper examines the ideals and realities of public service in this environment and explores the potential of new services to meet these demands.

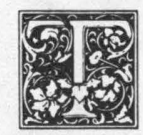

he growing importance of information in our society and the technology now available to access this information provide librarians with the unprecedented opportunity to take a leadership role in academic institutions. Yet, as the demand for service increases, funding is on the decline, confronting academic librarians today with a difficult paradox: as the explosion of information continues, we have been forced to forsake the ideal of acquiring all of the information needed by our patrons. As the tools available to access this information increase in number and sophistication, we can, ironically, offer only a portion of such resources to our patrons. The finite reality of our buildings, our budgets, and our staffs forces us to limit our collections and our services at a time when information and access to it are gaining importance in our society.

\section{TOO MUCH SERVICE?}

When considering the prospect of drawing the line on the services and resources we offer, one is struck by how antithetical the notion of "too much service" is to public service librarians. After all, most of us became public service librarians because we wanted to assist people. Yet often people ask for more help than we can reasonably offer. They demand materials that are not in our collections, services that overtax our resources, and answers that are beyond our individual capabilities. These requests are usually not unreasonable or out of the domain of academic librarians. Yet public service librarians face, on a daily basis, the reality of not being able to provide enough, because we do not have good ways of saying no.

Why? Because we are taught to say yes. $Y e s$, we can find the answer. Yes, we can help you find a book that will meet your need; if we cannot find the one you want, yes, we can locate a good substitute. And if we can't find a good substitute, yes, we can get you the one you identified from another library. We may not have exactly the thing you are looking for, but yes, we are sure we can find some way to help you.

Furthermore, we are taught to say yes to every request. Consider the first tenet of the ALA Code of Ethics:

Rebecca R. Martin is Associate Library Director for User Services \& Collection Development at San Jose State University, San Jose, California 95192-0028. 
Librarians must provide the highest level of service through appropriate and usefully organized collections, fair and equitable circulation and service policies, and skillful, accurate, unbiased and courteous responses to all requests for assistance. ${ }^{1}$ (Emphasis added.)

The underscored parts of this statement are admirable and establish an ideal, but in the context of today's libraries, is this goal possible? What does it really mean? And if we do not meet this ideal, how does that affect our views of ourselves and of our profession? In light of the ethics and the ideals of our profession, can we draw the line?

The value of meeting the information need is very strong in our profession. So is the value of equal service, and therein lies another paradox. To provide the same level of service to everyone may mean that we provide the highest level of service to no one. Is equality worth the price of inadequate service? If we say yes to everyone, does it mean that the service we provide our "primary clientele" is diminished?

To some degree, the answer to the latter question has to be yes. For some of our services, such as online searching and interlibrary loan, it is possible to offer service only to a primary clientele. But for our basic public services (access to the collections and reference assistance) it is usually not possible-or even desirable-to limit service. The answer to how we control the flow in order to prevent overextension may lie in the way we view and organize our services.

\section{THE REALITY GAP}

Before we consider these issues, we should take a closer look at our ideals. How does the reality of public service in libraries today match our ideals? As individual librarians, how do we cope with compromises and limits on the services we provide?

In a very perceptive article, Charles Bunge outlines the ideals of reference librarianship and examines the gap between those ideals and reality. ${ }^{2}$ Those ideals extend beyond reference to all public service librarianship. He finds that the joys of reference librarianship come from working directly with people. We give of ourselves as persons to help other persons; we tailor our response and service to the specific needs of the person we are serving. We help persons to learn and to know, and, as a bonus, our own knowledge grows in the process. Each reference question is an opportunity to learn more about information sources, more about our clients, and more about the world at large.

In a broader public service perspective, we have similar ideals for the programs and services we offer. We want reference desks that are staffed well enough to deal properly with all questions. We want collections that will meet at least the basic needs of our students and faculty. We want access systems that will allow these patrons to find the materials they need and to check them out when they need them. We want instruction programs that will enable us to teach patrons how to use these collections and services well. We want services that recognize the special needs of certain patron groups and make their library experiences successful. We want to harness the new technology to help us do all these jobs in a more beneficial manner. Most of us view these services as basic necessities, not blue-sky dreams of the ideal library.

But the reality is quite different. Information resources today allow librarians, more than ever before, to answer a wider range of questions more effectively and to tailor answers to the precise information needs and preferences of the patron. But do we have enough money to buy them? Or, if we have squeezed out enough money for a few, how do we decide which to choose? Do we have the time to learn to use these tools effectively? Do we even have a grasp of the multitude of new sources available to us in our libraries and computer centers and through our online systems and networks? And do we have the time to communicate effectively what we do know to our patrons?

And what about our patrons? Many librarians have observed that we see a much wider range of patrons on our campuses than ever before. Our faculty have more intense and diverse research inter- 
ests and needs. Our students come from more culturally diverse backgrounds, with varying degrees of basic skills and language capabilities. We have more students in reentry and extension programs, and we see more disabled students attending classes. In many academic libraries, we are seeing more community users. Each of these patron groups brings to the library a unique set of needs. A wider variety of users offers us a greater diversity of serious and legitimate questions, challenging us to use the full range of our skills and knowledge to find answers or to suggest sources and strategies for solution. But do we have time to provide the individual attention our patrons need? Are we prepared to provide special services? Does meeting the need of one patron detract from many others?

We are stretched further each day. As living costs rise for patrons, reliance on free services such as libraries increases. Academic institutions are not immune either to this additional library use or to the rising costs of operations. The result of these combined pressures is that our professional staffs have been reduced while the volume of activity has increased. Yet we have taken on new responsibilities in areas such as bibliographic instruction, computer searching, and outreach to special patron groups, in addition to more traditional duties. Involvement in campus and professional organizations, research, and publication may distance us from direct public service, leaving staff with less expertise to provide our frontline services. And resources to support collections, facilities, and automation continue to dwindle in the face of spiraling inflation and campus budget deficits.

\section{THE STRESS FACTOR}

The tensions between patron needs and staff capabilities cause personal and organizational stress. The line limiting how much service we can provide is often drawn for us due to lack of resources, lack of expertise, and lack of time. Staff members feel dissatisfied and frustrated as they perceive a gap between the ideal and the reality of librarianship.

\section{"The tensions between patron needs and staff capabilities cause personal and organizational stress."}

These feelings of dissatisfaction are not unique to librarians. Other public-service professionals in fields where the demand always increases to meet the supply of services experience them as well. By now most of us are familiar with the concept of "burnout," and at one time or another we have all suffered from its symptoms. There exists a classic cycle of burnout related to a project, an assignment, a job, or an entire profession. Enthusiasm for the undertaking, its challenges, and its problems is replaced by a sense of stagnation when solutions do not materialize and expectations are not met. This is followed by frustration with the system and the individual situation, which finally results in apathy. ${ }^{3}$

How do we deal with this? Michael Lipsky, in his work Street-Level Bureaucracy, describes the responses of publicservice professionals:

First, they develop patterns of practice that tend to limit demand, maximize the utilization of available resources, and obtain client compliance over and above the procedures developed by their agencies. They organize their work to derive a solution within the resource constraints they encounter. Second, they modify their concept of their jobs, so as to lower or otherwise restrict their objective and thus reduce the gap between available resources and achieving objectives. Third, they modify their concept of the raw materials with which they work - their clients-so as to make more acceptable the gap between accomplishments and objectives. ${ }^{4}$

If we stop to think about the compromises we have all made to help public service work within academic libraries, this pattern should seem familiar. We do the best with what we have. But if, in the process, we have lost the service ideal with which we started and reduced the needs of our patrons to fit within the limited services we can offer, can we still say we are fulfill- 
ing our purpose? Charles Bunge would put a darker cast on this response. He says,

Reference librarians perceive a gap between the ideals of reference librarianship that they believe and espouse and the realities of the reference service that can be practiced. The intensity of this perception has increased as funds have grown shorter and as we have become more and more aware of the complexity and immensity of the information needs of people in modern society and of the information resources available to serve them. To cope with the psychological dissonance caused by this perception, we stereotype our clients, respond to their needs in ways dictated by routines and procedures, blame them for their problems, and isolate ourselves from them. The unique needs and interests of the individual client have become less and less central to our value system and practice. These changes, however, only serve to perpetuate our feelings of dissatisfaction, guilt, resentment, isolation, and lack of confidence. ${ }^{5}$

Though this burnout is real, many public service librarians have maintained their integrity in the struggle against limitations. At times we all feel frustrated, but it is helpful to understand that this frustration is part of a larger problem for many public service professionals.

Many coping mechanisms for burnout exist, including emphasis on clientcentered service, development of support systems among colleagues, and continuing efforts toward self-awareness. Strong identification with a professional and individual value system is also essential. Librarians are coping well with these circumstances and are continuing to provide a high level of service, though constrained by limits on time and resources. Most librarians provide the best possible service, given the particular situation, to each patron who presents himself or herself at the desk, without reducing service to the level of lowest common denominator implicit in the notion of equal but inadequate service.

The concept of burnout, and the models for understanding and coping with it are closely linked to the notion of our service ethics and whether we can, in fact, draw a line in the services we provide. As individ- ual librarians, we must find ways to live with the compromises that must be made within the context of our system and still provide services that meet both the patrons' needs for information and our own ideals of public service. Drawing the line in providing service in the specific case is a personal and individual decision based on immediate circumstances, available resources, institutional policy, and, most of all, individual values. We need to keep these values intact if we are to make good decisions about the services we provide.

\section{ORGANIZATIONAL OVERLOAD}

Up to this point, we have looked at service limitations from the perspective of the individual librarian. It is also important to view these issues from an organizational and administrative perspective. Here, too, the ethical foundation is important, for the academic library's ideals must also be drawn from the parent organizationi.e., the college or university-of which it is a part. American universities and colleges are founded on the belief that the expansion of critical understanding and the development of individual autonomy are essential for a free and democratic society. ${ }^{6}$ The library's collections have always played an important role in this mission, but in recent years the library's public services have increased in prominence as more advanced research strategies and information-acquisition skills have become necessary to gain access to the growing amount of available information. The library's participation in the central mission of the university thus requires a commitment to reasoned inquiry, to the value of public discourse and scrutiny of contending opinions, and to the principle of free access to information. ${ }^{7}$ In public institutions, this commitment often extends beyond the students and faculty of the university to the surrounding community, to the region, state or nation, and to academe as a whole.

As the role of information in our society and in our universities expands, campus administrators are putting more pressure on libraries to respond. New demands to offer automated services, supervise com- 
puter labs, support faculty research, and meet the needs of a more diverse student population abound. At the same time, budgets have not kept pace with this changing library. Even traditional library functions such as collection building and reserve book rooms are not funded to operate effectively in today's economy. It becomes impossible to contend with physical constraints such as building size, inadequate wiring, and antiquated telecommunications systems when the academic institution itself is faced with little funding for capital improvements.

\section{"The notion of a primary clientele di- rectly contradicts our service ethic."}

As the demand from above and without increases with little or no new support, the pressures to provide service strain the library's budgetary, physical, and personnel resources. The threat of failure-both real and perceived-of both the individual and the organization forces administrators to weigh the ethics of their primary purpose against the realities of financial support from the larger institution. Thus, the manager looks for other ways to relieve these stresses. In this organizational overload, such decisions can result in the eclipse of lower priorities, an increased emphasis on the conservation of resources, and the reduction of standards of performance. ${ }^{8}$ As procedures and systems are streamlined to handle increased volume, attention to individual needs and problems diminishes. A factory atmosphere replaces the library's thinking atmosphere, making both the patron and the provider feel lost in an impersonal intellectual world rather than encouraged by the surrounding wealth of knowledge.

\section{PRIMARY CLIENTELE: A FALLACY?}

Given that today's academic libraries are, by their nature, in a state of overload in terms of both information and demand from the environment, it is easy to see how the notion of serving a primary clientele with a basic set of services has developed. Policies based upon restrictions in service can provide a buffer against the traumas of overload and burnout described above. But what of our users who do not fit into the standard categories? Do we ignore the needs of our disabled patrons or our reentry students? How do we serve those with language barriers or learning difficulties? Do we fail to recognize valid demands for library service that present themselves in unusual forms? If we are to hold to our professional ethic of the highest level of service to all requests for assistance and to our institutional ethic of individual autonomy and free access to information, we must address the unique information needs of our individual patrons.

The notion of a primary clientele directly contradicts our service ethic. When building collections, setting hours, and offering extended services such as microcomputer labs or interlibrary loan, consideration of the primary clientele can be an integral part of the decision-making process. But when providing access to information and assistance in locating it, limiting service to a primary clientele does not make sense.

Often we cannot tell whether the patron standing in front of us is a student, a faculty member, a student from another school, or a member of the community. Perhaps we can venture a guess, from the way they look or the question they ask, but to base the level of response to the inquiry on such questionable grounds would be inappropriate and even a disservice to our perceived primary clientele. Furthermore, even if we could identify the nonprimary user, given the growing importance of information in our society and our traditional belief in the values of access to information, it would be irresponsible to deny or limit their assistance. Our democratic society's fundamental belief in freedom of expression implies freedom of access to information. Therefore, it is the ethical duty of academic librarians, as librarians and as members of the academic institution, to guarantee that access and to resist any policy or practice that limits or denies it. We must not draw the line in 
the service we provide, but develop a circle which can encompass as many of the needs of as many of our users as possible.

\section{THE PATRONS' LIBRARY}

At the same time, overextending librarians at the reference desk does not make sense. The results of burnout are bad for librarians, for patrons, and for the library. We must find a way to ease the burden at the individual service point so that the interaction taking place there can be positive and productive.

To do this, we need to look carefully at the role of the librarian in providing access to the collection. The time when the librarian served as the key to the collection is long gone. The librarian's library, where resources were devoted primarily to building pristine collections, and where the best access was through the minds of a few librarians, is a library of the past.

Today's approach in academic libraries is to teach patrons to help themselves. We need to go one step beyond this and recognize that our libraries belong to the patrons. We need to listen carefully and become aware of their needs. We need to be creative in developing programs and services and in finding tools and technologies that will enable our patrons to help themselves. We need to view service at the reference desk as one of many tools available to patrons for access to their library and aggressively pursue alternatives, both to enhance their capabilities for finding information on their own and to protect the reference librarian from overextension. We need to assert our control over potentially chaotic situations by placing the knowledge of the library's resources in the hands of the patrons before they come to the library.

These ideas and solutions are not new. Many of our libraries have had extensive bibliographic instruction programs in place for years to provide students with ways to help themselves and to cut down on routine questions at the desk. Library handouts, workbooks, tours, orientation sessions, and information desks have all been developed for this purpose. Library instruction, integrated into subject-based curriculum, goes even further, preparing students for library research when they are most motivated to learn these skills. We have all worked to make it possible for our patrons to use our libraries, thus freeing staff for more direct public service work. We place a high priority in reference interactions on providing patrons not with the answers, but with the tools they will require to find the answers themselves.

\section{INNOVATION: WORTH THE EXPENSE}

We have also incorporated new technology, as it becomes available, to help our patrons use their library. Many of us are actively looking for online catalogs that are easy for our patrons to use, developing dial-up systems for downloading, and introducing CD-ROM systems to put online searching capabilities directly into the hands of our patrons. We are beginning to address the needs of disabled students with special equipment to make it possible for them to access our collections without extensive assistance.

\section{"We can make direct access to remote materials possible for our patrons and break down the barriers to infor- mation that our physical limitations and budgetary constraints create."}

We now have electronic systems that will open up resources to our patrons from far beyond our own collections. With the resource-sharing networks developed to support these systems, we can make direct access to remote materials possible for our patrons and break down the barriers to information that our physical limitations and budgetary constraints create.

Stretching already-tight budgets to meet these needs and develop these services is no easy task. We must actively and creatively pursue funding to support new and innovative programs. As we orient the library to the user, the need for trained personnel to manage instruction and develop new services will grow. We must work with teaching faculties and campus 
administrators to underscore the importance of information and raise the position of the library on the university's political agenda.

These programs and services may seem to be expensive investments of operating funds and staff time. But this investment will continue to pay off in helping us to maintain the quality of our public services in the face of an increasingly complex and ever-growing demand. By viewing the reference librarian as one source among many, rather than as the only source, we will extend our resources as far as possible to provide the access to information that our patrons need.

We must, therefore, not approach the need for new and extended services with the intention of drawing the line. Given the explosion of information resources and the growing importance of information in our society, the demands upon us can only increase. We must aggressively pursue new services and innovative programs if we are to extinguish burnout in trying to meet this demand. We need to avoid drawing that line wherever possible and remain open to new ways of providing service. We need to seek new methods of providing service if we are to maintain our ethic of providing free access to information and our ideal of providing the highest quality service to all of our users.

\section{REFERENCES}

1. American Library Association, "Librarians' Code of Ethics," American Libraries 13:595 (October 1982).

2. The following section draws heavily on Charles A. Bunge, "Potential and Reality at the Reference Desk: Reflections on a 'Return to the Field,' " Journal of Academic Librarianship 10:128-33 (July 1984).

3. Jerry Edelwich, Burn-Out: Stages of Disillusionment in the Helping Professions (New York: Human Sciences Press, 1980).

4. Michael Lipsky, Street-Level Bureaucracy; Dilemmas of the Individual in Public Services (New York: Russell Sage Foundation, 1980), p.83.

5. Bunge, p.131.

6. Elias Baumgarten, "Ethics in the Academic Profession," Journal of Higher Education 53:282-95 (May/June 1982).

7. Lawson Crowe and Susan H. Anthes, "The Academic Librarian and Information Technology: Ethical Issues." College \& Research Libraries 49:123-30 (March 1988).

8. R. L. Meier, Social Change in Communication-Oriented Institutions (Ann Arbor, Mich.: Mental Health Research Institute, Univ. of Mich., 1961).

9. Crowe and Anthes, p.129. 